\title{
Adesão à terapêutica da tuberculose em Pelotas, Rio Grande do Sul: na perspectiva do paciente
}

\author{
Tuberculosis treatment adherence in Pelotas, \\ Brazil, from the patient's perspective
}

Helen Gonçalves ${ }^{1}$

Juvenal Soares Dias da Costa 1

Ana Maria B. Menezes 2

Daniela Knauth 3

Ondina Fachel Leal 3

\footnotetext{
1 Departamento de Medicina Social, Faculdade de Medicina, Universidade Federal de Pelotas. Av. Duque de Caxias 250 , Pelotas, RS, 96030-002, Brasil.

2 Departamento de Clínica Médica, Faculdade de Medicina, Universidade Federal de Pelotas. Av. Duque de Caxias 250 Pelotas, RS, 96030-002, Brasil. 3 Antropologia Social, Universidade Federal do Rio Grande do Sul. Av. Bento Gonçalves 9500, Porto Alegre, RS 90509-900, Brasil.
}

\begin{abstract}
This study deals with adherence to tuberculosis treatment among men and women as well as the disease's links and consequences vis-à-vis life styles and treatment outcomes. The ethnographic study was a component of the Tuberculosis Epidemiological Control Project in the city of Pelotas and aimed to identify the reasons patients failed to complete treatment. Direct ethnographic observations and semi-structured interviews were used. Use of the term "adherence" is justified by the concern for extending to other fundamental factors in addition to the patient's own individual responsibility. This approach fostered an understanding of views towards disease, social dynamics among the various protagonists involved in the disease process, and treatment. Some of the factors considered in adherence to treatment were: socio-demographic characteristics, cultural factors, popular beliefs, the cost-benefit relationship, physical and chemical aspects of the drugs, the physician-patient relationship, and level of family participation in treatment.
\end{abstract}

Key words Tuberculosis; Patients; Drug Use; Anthropology

Resumo O trabalho aborda a adesão ao tratamento da tuberculose dentro do universo composto por homens e mulheres doentes e as conexões e conseqüências da doença na seu modo/fase de vida e no resultado final do tratamento. O estudo etnográfico, como um sub-estudo do Projeto Controle Epidemiológico da Tuberculose na Cidade de Pelotas, Rio Grande do Sul, propunha-se, inicialmente, verificar as razões existentes para que os pacientes não completassem o tratamento. Utilizou-se o método etnográfico de observação direta, conjugado com as entrevistas semi-estruturadas. A opção pela utilização do termo adesão é justificada pela preocupação em abranger outros fatores fundamentais, além da responsabilidade individualizada do enfermo. Esta abordagem possibilitou compreender as concepções de doença, as dinâmicas sociais entre os diversos protagonistas envolvidos no processo da doença e seu tratamento. Levaram-se em consideração alguns dos fatores implicados na adesão ao tratamento: características sócio-demográficas, fatores culturais, crenças populares, relação de custo benefício, aspectos físicos e químicos dos medicamentos, interação médico paciente e grau de participação familiar no tratamento.

Palavras-chave Tuberculose; Pacientes; Uso de Medicamentos; Antropologia 


\section{Introdução}

A tuberculose atinge a humanidade desde épocas remotas, mas somente no início da década de 40, do século XX, obteve-se a chance de curá-la com medicamentos. Com base nesses fatos, ressalta-se que estão vivas na história da doença as recomendações profiláticas e preventivas, dadas na forma de conselhos passados de geração em geração. Isso, de certa for$\mathrm{ma}$, assinala a dificuldade atual de lidar com os medicamentos, que em parte pode ser proveniente das próprias representações populares a respeito da cura da tuberculose.

A preocupação das autoridades sanitárias e o jogo político na construção de estratégias, para manutenção da população saudável, demonstra o poder do controle médico e estatal como legítimo sobre as questões que lhe competem. Atualmente, com a padronização do tratamento da doença, com a qual se esperava o controle da enfermidade, vieram à tona discussões antigas tais como o modo mais eficaz de combater as falhas do tratamento da tuberculose. Atualmente, o maior problema apontado no tratamento da tuberculose é a não adesão (Picon et al., 1993; WHO, 1997); por conseqüência os índices de incidência, mortalidade e de tuberculose multiresistente estão aumentando. Avaliar o Programa depois de alguns anos de existência parece ter se tornado inevitável. O modo de viver e de pensar dos indivíduos não está muito distante, no entanto, muitas das discussões limitam-se a resumir e avaliar respostas sem compreender a visão de mundo dos doentes e seus familiares. O ponto de vista do paciente e o envolvimento do contexto social no seu comportamento amplia a discussão para além das fronteiras da clínica. As representações de saúde/doença e as concepções sobre a etiologia e o contágio da tuberculose demonstram que a sabedoria e a prática dos pacientes não se restringem aos ensinamentos médicos, pelo contrário, há um amplo leque de possibilidades e articulações que fogem ao controle do Programa de Controle da Tuberculose (PCT). As pesquisas sociais e comportamentais sobre as pessoas que continuam ou não seu tratamento são importantes também para acompanhar e atuar nas mudanças epidemiológicas das doenças (Sumartojo, 1993).

O objetivo deste trabalho é abordar a adesão do ponto de vista do doente, apontando para as conexões entre sua fase de vida, via a categoria gênero, e o resultado final do tratamento (adesão ou não adesão).

\section{Metodologia}

O Projeto Controle Epidemiológico da Tuberculose na Cidade de Pelotas, Rio Grande do Sul, incluiu diversos subestudos. Objetivou avaliar fatores de risco e incidência para casos novos de tuberculose, em pacientes de 20 a 80 anos, com duração de junho de 1994 a junho de 1995 , com acompanhamento por mais seis meses (Menezes et al., 1998). O estudo etnográfico, como um subestudo, propôs-se a verificar as razões existentes para que os pacientes não completassem o tratamento. Utilizou-se o método etnográfico de observação direta, conjugado com as entrevistas semi-estruturadas e o uso de dados quantitativos. A primeira fase do trabalho de campo teve como objetivo manter contato com os profissionais e agentes de saúde do Centro de Saúde (CS), único local a tratar a doença na cidade. Pelo estudo epidemiológico foram realizados controles sucessivos da adesão ao programa. Aqueles que durante os primeiros meses de pesquisa não compareceram ao local para retirada do programa eram visitados em suas casas e conversas informais eram iniciadas. Não houve qualquer caso de negação do diagnóstico da doença, visto que as entrevistas iniciais abordavam as características do CS como uma instituição de saúde. Os informantes não se constituíram unicamente de não aderentes, aqueles que retornavam mensalmente também foram abordados por meio de um sorteio aleatório.

\section{Características da população do estudo etnográfico}

O universo da pesquisa foi composto por um grupo de homens e mulheres que procuraram o CS e tinham começado o tratamento para tuberculose há pelo menos um mês. Os informantes foram abordados em diferentes períodos dos anos de 1994, 1995 e 1996, totalizando um grupo de 50 indivíduos entre 16 e 81 anos.

Foi contatado um número maior de homens $(\mathrm{n}=35)$, grande parte deles estava desempregada ou fazendo serviços gerais eventuais. A diferença entre o número de homens solteiros e casados foi muito pequena, seguido em ordem decrescente dos homens separados. As mulheres eram casadas na sua grande maioria, donas de casa ou faziam trabalhos esporádicos, como vendedoras ocasionais. Apenas três tinham cargos burocráticos, com carteira assinada. As solteiras moravam com os pais ou só com a mãe, e não exerciam nenhuma atividade remunerada, enquanto foi mantido con- 
tato. A faixa etária mais entrevistada foi entre os 20 e 40 anos, para os dois grupos.

Já se poderia pensar que a explicação, antes válida, sobre o peso do trabalho na vida do doente (homem "provedor") não se manifesta hoje da mesma forma, ou pelo menos, como uma causa imediata. Porém, os trabalhos realizados anteriormente à doença exigiam uma exposição física constante às variações climáticas (pedreiros, varredores de rua) e ofereciam poucas condições de salubridade, além da baixa remuneração e exigência de força corporal. O mesmo não pode ser dito do trabalho feminino e de suas concepções sobre a origem da doença.

\section{Compliance e adherence: as diferenças}

“Adesão" e "abandono" são os termos utilizados pelo Programa de Controle da Tuberculose. Na prática diária do CS, somente a palavra “abandono" é utilizada, sendo "adesão" a expressão empregada pelas publicações oficiais do Programa. Existem outros termos em uso na bibliografia consultada; frente à diversidade de termos, a discussão sobre o assunto não se esgotou e nem chegou a um consenso. Em diferentes épocas, debate-se qual a perspectiva política e social que pode melhor contemplar e explicar as atitudes dos pacientes frente às imposições terapêuticas que exigem um tratamento continuado por um período prolongado.

As diferenças conceituais encontram-se norteadas por teorias que contemplam um aspecto e excluem outro. Compliance e adheren$c e$ são termos discutidos freqüentemente nas pesquisas que procuram explorar e problematizar estes conceitos na prática clínica das enfermidades. O termo compliance estaria mais centrado na ideologia biomédica, sendo o paciente visto como um cumpridor de recomendações (Conrad, 1985). O indivíduo doente é tratado com pouca (ou nenhuma) autonomia para desobedecer às recomendações médicas. Na relação médico-paciente, em tese, o comportamento do doente e o controle da situação é parte do profissional. Nesse caso, quando médico e paciente não possuem uma interação e comunicação adequada, em grande parte, já está explicitado o porquê da noncompliance. Como Conrad (1985) enfatiza, este conceito não abarca outros aspectos de semelhante valor para discussão, quais sejam, as opiniões e interferências: da família, do trabalho, dos vizinhos, as representações de saúde, corpo e doença. Ao desconsiderar a inter-relação entre os fatores presentes no todo, reduz-se a compreensão dos comportamentos “desviantes", sendo esses o alvo pouco certeiro dos programas de saúde. Trostle (1988) contribuiu para o enfoque da relação assinalando que compliance acaba por enfatizar os limites da própria disciplina médica.

Partindo da concepção de que os motivos para a não conclusão do tratamento, como recomendado, são múltiplos, a perspectiva centrada no modelo biomédico não oferece suporte suficiente para compreender a necessidade de controle e o manejo da doença, por parte do médico, e a decisão favorável ou não do doente ao tratamento (Farmer, 1997). Muitos pacientes, com doenças crônicas, despendem uma parte de suas vidas no "papel de paciente" e, nestes casos, a relação médico-paciente é um dos fatores importantes na decisão de seguir ou não as recomendações médicas (Conrad, 1985). Segundo Chaule (1990) a compliance é o resultado de um processo que envolve uma série longa de responsabilidades, desde a tomada de decisões do Ministério da Saúde até o tratamento médico ambulatorial.

Já os termos adherence (ou adhesion) procuram ressaltar a perspectiva do paciente, como um ser capaz de uma decisão mais consciente e responsável por seu tratamento. Farmer (1997) chama a atenção para a impossibilidade de abarcar todos os pontos de vista do paciente. Adesão compreende que todos pacientes têm uma autonomia (patient agency) e uma habilidade para aceitar ou não as recomendações médicas; algumas vezes, o termo tem a conotação de desresponsabilizar ou amenizar o dever da prática médica, enquanto provedor e participante ativo deste processo de cura. Assim sendo, se o paciente não adere (nonadherence) ao tratamento é porque ele assim escolheu; não é de responsabilidade do sistema, do PCT, dos médicos. Entretanto, a autoregulação do tratamento não desresponsabiliza a saúde pública, pelo contrário, exige que uma política adequada de atendimento e cura seja oferecida à população em geral. O significado e o manejo da medicação, na vida diária dos doentes com tuberculose, têm uma forte influência na sua adesão ao tratamento. O tratamento irregular ou incompleto compromete a cura e o controle da tuberculose; a adesão é um objetivo a ser alcançado do início ao fim para manter a eficácia do Programa. Com a comprovação de que alguns indivíduos doentes não respondem às recomendações terapêuticas, desenvolveram-se programas de saúde cada vez mais "controladores" para as enfermidades infecto-contagiosas. 
Neste trabalho, a opção pela utilização do termo adesão é justificada pela preocupação em abranger outros fatores, para além da responsabilidade individualizada do enfermo. A escolha de um termo mais adequado não soluciona e/ou privilegia ambas as perspectivas; a diferença está no olhar dirigido à pesquisa e não somente no termo. Estudos que destacam a perspectiva médica e do paciente utilizam tanto o termo compliance como adherence (Barnhoorn \& Andriaanse, 1992; Liefooghe et al., 1995).

\section{As definições na prática}

O papel desempenhado, na maior parte da vida dos indivíduos contatados, não foi o de doente, sendo assim, a abordagem não pode limitar esta visão a um âmbito, sem considerar a influência da doença na vida diária da família e de outros. Os informantes não se definem aderentes ou não aderentes, narram que tomam ou não tomam seus remédios. A grande maioria dos pacientes são comunicados da possibilidade de serem rotulados como "abandonos" pelo Programa, em razão disso temem que não consigam mais um tratamento gratuito, caso a doença retorne; ou se sentem ameaçados e dissuadidos a simular a adesão quando a perspectiva do paciente se sobrepõe à do médico. Seguir o tratamento medicamentoso pode ser definido como um ponto no qual o comportamento das pessoas adoecidas coincide com o aconselhamento médico (Haynes et al., 1979).

O termo adesão está sendo utilizado quando há, principalmente, concordância entre o comportamento do paciente e a prescrição da ingestão diária de, pelo menos, metade dos medicamentos necessários. O critério para a definição de não adesão em relação aos medicamentos foi o seguinte: o doente "desobedecer” a prescrição médica, como comportamento constante, ou seja, não ingestão diária do número de medicamentos estipulados. Foi também considerado para definição de adesão o confronto entre o comportamento do informante e as prescrições médicas, como: o repouso, a alimentação, o consumo de bebidas ou fumos proibidos, as precauções para evitar contágio de outros, o retorno mensal ao CS e a realização de exames clínicos. O estudo de Perini (1998) alerta para o período de festas quando o consumo de álcool e fumo é maior e colabora para o abandono do tratamento.

\section{Fatores que influenciam a adesão ao tratamento}

A presença de sensações corporais desagradáveis lembra constantemente ao paciente que ele ainda está com algum problema decorrente da sua doença atual. Alguns indivíduos, quando os sintomas melhoram, acreditam que não estejam mais doentes, já que a concepção de doença está ligada à presença de sintomas indesejáveis que não os permitam agir como antes (Fox et al., 1987; Bloom \& Murray, 1992; Menegoni, 1996; Nair et al., 1997; Gonçalves, 1998). Tomar os medicamentos é reviver a doença que não mais se manifesta fisicamente (Conrad, 1985).

A adesão depende também de como o indivíduo doente controla e articula o seu corpo e qual a sua visão do que é ou não uma boa resposta do corpo às sensações desagradáveis. Quando percebe que a melhora depende do seu comportamento, tende a seguir, o mais corretamente possível, a terapêutica.

São também consideradas importantes como indicadores de não adesão algumas variáveis demográficas e sócio-econômicas como idade, sexo, raça, ocupação, estado civil, renda e educação que são freqüentemente incluídas nos estudos sobre tuberculose (Barnhoorn \& Adriaanse, 1992; Mangtani et al., 1995). No entanto, há estudos em que estas variáveis são vistas como inconsistentes e estão apontando para outros fatores sobre o paciente para medir a não adesão (Hulka et al., 1975; Sumartojo, 1993). Em Pelotas, o componente quantitativo do Projeto não revelou nenhuma variável sócio-demográfica como consistente para medir a não adesão ao tratamento, exceto cor da pele. A taxa de não adesão encontrada, durante o período de estudo, foi de $20 \%$ (Dias-da-Costa et al., 1998).

Em muitos países o tratamento para tuberculose é pago, e algumas falhas são apontadas como decorrentes da baixa condição econômica dos indivíduos acometidos pela doença (Liefooghe et al., 1995). No Brasil, o tratamento padronizado da tuberculose é custeado pelo Governo, mas nem por isso o índice de "alta por abandono" tem sido reduzido, indicando que outras questões são mais relevantes para a decisão. Em Pelotas, foi possível perceber alguns investimentos baseados em uma avaliação de custo e benefício. Os gastos com alimentação e passagens de ônibus são um exemplo. A família que não possui condições econômicas para arcar com tais gastos, especialmente quando o doente é o provedor(a), mobilizase para que não seja isto um impedimento pa- 
ra a cura do doente. O investimento (não previsto e pesado no orçamento doméstico) lhes garante a possibilidade de que esta pessoa venha a se curar mais rapidamente e retomar suas atividades produtivas o quanto antes. Alguns pacientes chegam a atribuir a interrupção do tratamento às dificuldades financeiras. Contudo, hábitos como comprar cigarros ou beber cervejas ou refrigerantes não foram abandonados. A distância da casa e a dependência de transporte para ir ao CS foi comentada várias vezes, mas não como a causa mais relevante. Comportamentos semelhantes também foram demonstrados nos estudos de Fox et al. (1987) e Picon et al. (1993).

As relações de custo e benefício do tratamento devem ser também consideradas. Murray et al. (1990) e Liefooghe et al. (1995) indicam que a percepção da eficácia do tratamento da tuberculose, pelo paciente, é fundamental para a adesão, e que isto se dá também em função da relação custo e benefício. Esta relação pode ser estudada pelo tempo que o paciente despende para ir ao CS, adaptar-se ao tratamento, fazer exames, consultar e buscar medicamentos. Esta mesma relação pode ser levada a outro plano: a relação entre as pessoas envolvidas com o indivíduo doente. Os laços familiares ou de amizade requerem um certo grau de investimento, pois o indivíduo deve modificar ou moldar-se às exigências do seu meio para mantê-las estáveis, seja indo ao médico ou ingerindo as drogas.

A interação entre médicos e pacientes tem sido identificada como importante, tanto para os que interrompem, como para os que não concluem o tratamento da tuberculose (HayesBautista, 1976). Pacientes que não confiam no sistema de saúde ou nos médicos são mais propensos a não aderirem ao regime medicamentoso (Hulka et al., 1975; Garrity, 1981; DiMatteo et al., 1993). Insiste-se que a perspectiva do paciente tem de ser levada a cabo nas decisões e na negociação com o médico sobre as regras terapêuticas. O médico não deve desconsiderar o manejo do paciente sobre o tratamento, em nenhum momento. DiMatteo et al. (1993) argumentam que o médico que atende um maior número de pessoas doentes, por semana, tem pacientes mais aderentes, talvez por encontrá-los mais freqüentemente. Em Pelotas, o médico que mais atende é o que tem menos tempo para escutar as queixas e dúvidas dos pacientes, no entanto, para os informantes, é o profissional mais competente e dinâmico. A explicação dada para a preferência se resume na sua capacidade de detectar e medicar corretamente as complicações do tratamento, além das sensações corporais negativas trazidas com a tuberculose ou mesmo com sua medicação.

Os efeitos das drogas e as reações ao tratamento envolvem questões igualmente importantes para a adesão. Segundo Liefooghe et al. (1995) são as expectativas do tratamento e da cura; a motivação para a manutenção da saúde; as vantagens pessoais de seguir com a terapêutica, além dos benefícios do regime de tratamento que demarcam alguns comportamentos durante a terapêutica. Alguns indivíduos doentes consideram os medicamentos fortes o suficiente para afetar negativamente outras partes do corpo ("conserta uma coisa e estraga outra"). Tanto uma concepção quanto outra pode levá-los a não adesão.

Não pode ser descartado o papel da cultura nas concepções populares de doença, o que tem sido amplamente discutido, em contraposição à visão positivista da doença. O conhecimento e as crenças sobre o tratamento são fatores importantes apontados para a adesão, como demonstram os estudos de Murray et al. (1990), Farmer et al. (1991), Barnhoorn \& Adriaanse (1992) e Menegoni (1996).

Essas mudanças devem estar atentas para o grau de participação da família durante o período de cura. Liefooghe et al. (1995) relatam que um paciente, ao receber o diagnóstico de tuberculose, leva um choque ou tem dificuldade de aceitá-lo inicialmente. Além disso, não é o único a ser afetado, a família nesse momento desempenha uma importante função. Seus dados demonstram que nem sempre o suporte familiar traz resultados positivos; em alguns casos a família pode influenciar negativamente a seqüência correta da terapêutica. Em Pelotas o contrário foi encontrado, a participação familiar se mostrou extremamente importante para o seguimento do tratamento.

\section{A relação dos medicamentos com a Medicina e com os informantes}

Além dos efeitos físico-químicos sobre o organismo, os medicamentos têm determinadas "funções" nas sociedades, tais como: a maior racionalização do tempo de consulta clínica; aumento da produtividade do médico e do sistema de atendimento à população; o reforço nas relações de poder sobre o paciente e seus familiares; e auxílio na construção do diagnóstico das enfermidades (Rozenfeld, 1989). A relação dos informantes doentes com os medicamentos nem sempre é simples e se restringe ao seu consumo, ainda que se constitua no único 
recurso médico possível para a cura. Alguns dos informantes com tuberculose observam as características dos medicamentos e, valendose delas, fazem uma avaliação da doença e do tipo de tratamento dispensado, como se demonstra a seguir. A medicação do tratamento é apresentada de duas formas - cápsulas (rifampicina) e comprimidos (pirazinamida e isoniazida). As cápsulas são muitas vezes abertas pelos doentes, para a investigação do seu conteúdo. Um dos comentários comuns é a cor do pó (do medicamento), além da própria cor (externa) da cápsula (vermelha). Geralmente, a cor vermelha, para os informantes, está associada à potência/força do medicamento, ou seja, se o pó e o invólucro (da cápsula) são destas cores significa que é um remédio mais forte. No entanto, o outro medicamento - o comprimido tem um tamanho maior que os comprimidos mais consumidos no cotidiano e por isso também é considerado forte. Este comprimido é branco, porém seus efeitos colaterais (náusea e vômito) parecem ser menos tolerados pelos doentes. Como a grande maioria dos pacientes toma os comprimidos e cápsulas, separadamente, consegue detectar as diferenças das sensações e assim formula opiniões específicas sobre cada remédio tomado. Aqueles que ingerem todos juntos, em um mesmo horário, fazem distinção de alguns efeitos colaterais com base no gosto deixado na boca. Os pacientes sugerem que quando nauseados sentem o gosto, permitindo uma identificação do medicamento considerado mais forte ou ruim. Segundo as observações e falas dos pacientes, é grande a probabilidade de que este seja o medicamento mais rejeitado e com maior dificuldade de aceitação, durante a terapêutica. Todavia, foi observado que quanto maior for a irregularidade na ingestão destes medicamentos, menor é a probabilidade de que cessem os efeitos negativos; contrário ao que ocorreria com o paciente que mantém a ingestão constante dos medicamentos. Segundo Sbarbaro (1980) os efeitos adversos do tratamento complexo e extenso não têm representado um impacto considerável na adesão do paciente, "no entanto, efeitos colaterais são listados como motivo para noncompliance em 5 a 10\% do período".

Os problemas familiares e individuais enfrentados por estar/ser doente são talvez mais importantes para o seguimento da terapêutica do que o tamanho dos medicamentos. O tamanho pode ser apenas um dos indicadores utilizados para afirmar e defender seu posicionamento de não administração correta frente à família e o médico. Assim como o tamanho, outros recursos (gosto, efeitos colaterais, alte- ração no número de medicamentos a serem ingeridos) podem ser empregados para reafirmar a posição de tomar regularmente ou não tomálos - ou seja, para não afetar a relação desses indivíduos com os demais do seu círculo de relações primárias (categorias influentes como: honra, posição e papel familiar do indivíduo doente). Com isso, não se afirma que o gosto, ou tamanho ou os efeitos colaterais inexistam ou que sejam apenas justificativas, mas que uma parcela dos adoecidos incrementam estas características inerentes ao tratamento para manipulá-lo. A relação com a cura da doença, para muitos indivíduos doentes, não é apenas uma questão de ingestão de medicamentos; existem outros panos de fundo que perpassam todo o tratamento. Como se sabe, a doença afeta muito mais do que o corpo biológico.

Fundamentados nessas conclusões sobre os efeitos desejáveis ou não dos medicamentos, os doentes administram seu tratamento de modo que as sensações negativas sejam minimizadas. Para amenizar o sabor e os efeitos negativos, ingerem os medicamentos com leite, café ou alimentos de sabor mais picante, que elimine logo o gosto deixado pelo "remédio" na boca. Outros preferem dividir as doses, tomando metade durante o almoço e o restante à noite. Há ainda aqueles que dividem o comprimido, partindo-o em dois, para engolir com maior facilidade. O tamanho, para alguns, muitas vezes influencia mais na decisão e no ato de ingeri-los do que a coloração e o sabor.

Mariana: "Eu não consigo engolir, não adianta! Mas agora tenho, senão vão me mandar de novo para o Sanatório e eu não vou para lá."

Francis: "A senhora olhe se é possível engolir isso [mostra os medicamentos e comenta:-duas balas [calibre] 22 e quatro rodas de carreta!".

Uma atitude contrária, que indica a necessidade de ingerir um número maior de medicamentos do que o previsto pelo tratamento, foi encontrada em apenas uma informante. Ela se culpou por ter contaminado seu filho de 12 anos; acredita que tomando por mais dois meses teria sua imunidade garantida contra novas investidas do bacilo e assim garantiria saúde para a família. Neste sentido, mais saúde (correspondente à falta de sintomas e fortalecimento do organismo) pode ser adquirida via medicamentos.

\section{Elementos do "descaso"}

Na situação de consulta, estes elementos referentes à coloração e ao tamanho não aparecem, ou são considerados secundários. Quan- 
do há referência por parte dos pacientes, os médicos procuram desfazer qualquer impressão negativa já associada ao(s) medicamento(s). Além disso, os efeitos colaterais mais leves (náusea e vômitos com pouca freqüência) e a coloração alterada da urina, por exemplo, são queixas e comentários feitos pelos doentes que demonstram a importância de outros fatores para a conclusão da terapêutica. A despreocupação com a conservação da saúde e a ênfase no tratamento da doença (Dixon, 1981) faz da política atual de saúde pública para a tuberculose uma intervenção pouco eficaz. Pode-se questionar por que os pacientes com dúvidas e reclamações sobre os medicamentos não procuram modificar seu comportamento, inquirindo os médicos a darem explicações mais claras. A resposta não é simples; perguntar e ouvir são atitudes comuns no local. Porém, a resposta dada, nem sempre leva à compreensão da questão. Muitos sentem-se acuados pela situação evidente do desnível social e do poder existente na situação pré-definida entre médico-paciente, durante uma consulta. Por necessitarem de um convívio mais prolongado, alguns pacientes procuram evitar situações em que possam ser criticados. Os que perguntam, nem sempre compreendem a explicação dada pelo profissional e sentem-se constrangidos de solicitar novos esclarecimentos; uma situação que mostra como os desníveis de entendimento variam. Portanto, obedecer à prescrição dos medicamentos é além de concretizar a doença efetivar as suas limitações.

\section{O comportamento diante dos medicamentos e a adesão}

Entre homens e mulheres existem características que são mais concernentes às pessoas de um determinado "grupo", mesmo que seja ele delimitado por papéis sociais esperados. Esses manejos e dinâmicas, no decurso da terapia, aliados a valores, às características e aos contextos familiares e individuais, vistos aqui inicialmente, baseados em categorias como etiologia e contágio, permitem entender algumas das diferenças na adesão entre os gêneros. A forma como lidam com a doença e a influência dessas diferenças no resultado final do tratamento são importantes para fazer correlações e levantar hipóteses, que ampliam as possibilidades de entendimento dos comportamentos e do PCT. Os homens e as mulheres foram divididos basicamente em "grupos" de caráter unicamente analítico. O momento de vida ou fase de vida em que se encontram ajudam a perce- ber e delimitar alguns comportamentos como mais adequados a uns e menos a outros.

O medicamento, por si só, tem pelo menos dois sentidos com significados contrários (Lefèvre, 1991): o positivo, que está relacionado à cura e ao restabelecimento da saúde; e o negativo, no qual estão colocados os efeitos colaterais, o tamanho e o gosto. A adesão ao tratamento da tuberculose tende a diminuir quando o corpo reage bem; saúde física equivale a ausência de sinais físicos desagradáveis. Porém, o contrário também pode ser plausível quando os sinais não cessam, mesmo após concluído o tratamento, o paciente não se conforma, acredita na incompetência do médico para lidar com a doença e a leitura dos exames. Essas reações aos medicamentos, em conseqüência à doença e ao tratamento dela, podem ser analisadas conforme a fase de vida do paciente (estado civil) e as características sociais atribuídas ao gênero desse paciente. Mesmo que pareça incomum, a classificação entre indivíduos doentes casados, separados ou solteiros se mostrou importante para agrupá-los; sem reducionismos, argumenta-se que o momento de vida atual e os laços estabelecidos e requeridos socialmente, neste período, são algumas das formas de delimitá-los, mas não únicos.

\section{Homens e mulheres solteiros e separados: os manejos para a (não)adesão}

No estudo foi possível observar que os homens mais jovens solteiros e os separados têm, aparentemente, preocupações mais diluídas sobre a doença e aderem menos às recomendações médicas. Procuram preservar seu modo de vida (festas, bebida, fumo) sem alterações, mesmo quando debilitados fisicamente. Talvez, isso ocorra pela importância que atribuem à imagem e pela posição ideológica de homens (autônomos, livres, independentes), que não acreditam poder esmorecer com dores corporais e com doenças, muito menos modificarem alguns hábitos, durante um período de seis meses. Na grande maioria, entendem que uma vez cessados os sintomas da doença estão, se não totalmente, quase curados. Alegam que os medicamentos são em grande quantidade e que provocam efeitos colaterais. Assim sendo, a adesão, tal como é requisitada pelo PCT, não ocorre na grande maioria desse grupo. Para eles, os efeitos colaterais dos medicamentos, quando muito fortes, são uma maneira de demonstrar, principalmente para si, que a tera- 
pêutica, tal como prescrita, causa-lhes tanto ou mais problemas do que os sintomas iniciais; o erro médico pode ser uma das justificativas. Sabe-se que o tratamento abarca outras dimensões que não somente da ingestão dos remédios. Envolve fatores do dia a dia pessoal e familiar para a recuperação da forma física e para o retorno às atividades anteriores. Para os homens o fator de maior impacto é a interrupção de sua rotina, principalmente aquela relacionada com o trabalho e com as suas saídas com amigos, envolvendo ingestão de bebida alcoólica.

A relação desse grupo com os medicamentos é restrita ao alívio dos sintomas; a concepção que prevalece é a do medicamento como reparador da doença; relação distinta, na prática, de outro grupo - os homens casados, pais e "provedores" da família. No estudo foram contatados 12 homens com algum problema familiar ligado ao alcoolismo - desses, oito tiveram "alta por abandono" do CS; um (e único) homem com HIV faleceu durante o estudo - os medicamentos para AIDS não estavam disponíveis e os da tuberculose eram ingeridos irregularmente; dois homens eram indigentes: um interrompeu temporariamente e o outro recebeu "alta por abandono" do local. Esses são indivíduos que requerem uma atenção e um manejo diferenciado, para discutir qual a sua "real" possibilidade de participação no processo de cura médico e a melhor forma de conseguir uma parceria mais eficaz. Além disso, são esses os que têm chance aumentada de virem a desenvolver bacilos resistentes às drogas atuais e, ainda, de disseminar esta nova forma mais resistente de tuberculose.

Entre as mulheres solteiras não houve queixas ou menção de problemas com álcool (mesmo dos familiares) e AIDS. Nenhuma das mulheres do grupo pesquisado é ou foi indigente. As mulheres solteiras e a única separada do grupo acreditam que a doença não é tão grave como inicialmente pensavam - "tem cura"; isso parece ser o suficiente para o desleixo com as regras terapêuticas. Mas a preocupação e a pressão da família, com a possibilidade de não adesão, estimula-as para a conclusão da terapêutica. Em grande parte dos casos, elas recebem "alta por cura", embora omitam para o médico algumas alterações no tratamento. As alterações mais freqüentes são ingestão irregular, não modificações de hábitos considerados prejudiciais, como a má alimentação, pouco repouso e fumo.

Homens e mulheres solteiros e separados consideram os medicamentos ruins e relatam, com mais intensidade, os efeitos adversos. No entanto, são as mulheres que apontam para esses efeitos com maior preocupação em relação às seqüelas posteriores ao tratamento. Para algumas, o remédio é um mal necessário, contudo passível de manipulação para diminuir o desconforto dos efeitos colaterais. Não tomar diariamente faz com que os efeitos indesejáveis sejam menos freqüentes. Para todas as mulheres, a necessidade e o desejo de cura, quando as sensações desagradáveis se intensificam, faz em com que superem as sensações desagradáveis dos medicamentos, no seu período mais crítico.

Os homens separados e os solteiros têm maiores dificuldades em aderir ao tratamento, em parte porque acreditam na resolução da tuberculose sem necessidade de tantos medicamentos receitados. Ao perceberem uma redução dos sintomas diminuem o número de medicamentos ingeridos, queixam-se nesse momento mais do tamanho e menos dos efeitos adversos. Também, como as mulheres solteiras, omitem dos médicos que auto-administram seu tratamento. Manejam a quantidade diária ingerida, em função de suas sensações corporais, aliadas aos eventos de seu dia a dia. De certa forma sabem que não estão agindo conforme recomendações, a cobrança médica pode ocorrer e o seu "castigo" seria a hospitalização ou a mudança de esquema de tratamento. Contam, sobretudo, com o apoio da mãe e irmãos, durante o processo de cura. Bertolozzi (1998) também aponta para a importância do respaldo familiar durante a cura. O medo do hospital é oriundo de suas experiências e de relatos do local, acrescido ao temor de ficarem distantes dos familiares. Nesse grupo, observase que a doença se concentra primordialmente no sintoma; nele, também, foi encontrado o maior número de "esquecimentos" da ingestão das drogas. As narrativas expressam a dificuldade de lembrar de algo que não é mais visível ou perceptível em seus corpos. O consumo regular, durante os seis meses e na dosagem préestabelecida, não se faz necessário, segundo alguns doentes, pois antes do término previsto para o tratamento, os sintomas já não estão presentes. A doença, nesses casos, assume uma proporção mais física, inicialmente, do que moral, embora este segundo aspecto siga existindo. O aspecto físico garante o moral, isto é, um corpo "capaz" (forte, íntegro para o trabalho) leva o moral a não ficar tão afetado durante a enfermidade perante a família. O controle do corpo físico saudável os mantém dentro de um quadro ajustado ao seu meio social. Quando o corpo físico não corresponde a suas necessidades, deve ser ajudado (com remédios e 
alimentação, por exemplo). A procura do serviço de saúde se dá nestes momentos, ou seja, em ocasiões de muita debilidade física - quando o corpo não consegue cumprir com seus afazeres diários, quer no lazer, quer no trabalho. Uma vez que a força física retorne e os sintomas se esgotem a um mínimo aceitável, parte dos pacientes relaxam o seu tratamento. Assim que os sintomas retornam, alguns pacientes voltam ao tratamento de forma mais regular. Outros ficam anos neste ciclo, de "abandono" e "retratamento" - "velhos fregueses nossos", diz a assistente social do CS, caracterizando-os.

Para a maioria dos que interrompem o tratamento temporariamente o médico intervém, explicando-lhes mais enfaticamente como devem proceder com os medicamentos. Nesse momento, algumas dúvidas, que até então não haviam sido sanadas, são esclarecidas; muitas delas nem sequer constituíam uma incerteza, mas um desconhecimento. Nestes casos, o novo posicionamento médico permite que o paciente entenda e, embora a associação pareça forçada, cumpra de uma forma mais regular (com adaptações próprias) com o que lhe é determinado fazer, durante o tratamento.

Ao questionar estes indivíduos se não sofrem pressão familiar para seguirem seu tratamento, as respostas são, na sua grande maioria, “sim” e "não". Em alguns casos a família tenta controlar, administrando o tratamento, mas só consegue durante certo "tempo", quando os sinais da doença estão mais acentuados. Em outros casos, a família desconhece a forma correta de administrar os medicamentos e acredita que o paciente o faça conforme orientação médica. Houve ainda casos nos quais o próprio paciente manipulou esta informação, para evitar que interferissem em sua decisão.

Mariana: "Ah não, a mãe pensa que eu estou tomando tudo direitinho.

[diz a mãe:] “- Estás tomando remédio?” Estou mãe!;

[mãe:] “- Trouxeste?” Trouxe mãe!

Eu tomei um na frente dela. Ela pensa que eu tomo (...) Se a mãe sonha, a mãe me mata! A mãe vem com sermão também."

Ainda é possível indagar se, no que se refere à concepção de corpo e do modo de vida, os familiares não compartilhariam da mesma visão do indivíduo doente, visto que discordam quando descobrem que estão reorganizando, a seu modo, a dosagem dos medicamentos. Os familiares não reconhecem a melhora física/ corporal da mesma forma do que o doente, assim como não concordam com seu modo de vida. Acredita-se que a diferença, aqui, seja marcada pela preocupação com o outro, um ente querido e, neste sentido, o controle familiar se alia ao poder de cura médico.

\section{O papel dos casados: responsabilidade e o tratamento}

Os homens casados procuram seguir corretamente o tratamento e acreditam que possam retornar às atividades com o mesmo vigor que possuíam antes, embora comentem não se sentirem "os mesmos" (menos força, cansam-se mais rapidamente). São eles que têm os salários mais altos da família. Talvez, por essa razão, a categoria trabalho é a via pela qual as preocupações, referentes ao seu "papel social", melhor se expressam e são socialmente legitimadas. É para a esposa que confiam suas fragilidades e inseguranças em relação à doença. Escondem seu adoecimento do restante da família, vizinhos e amigos com medo da estigmatização (Goffman, 1988). A auto-estima e a auto-estigmatização desse "grupo" são um ponto frágil, pois desempenham funções e papéis bastante definidos que, quando alterados, em alguns pontos, os mobilizam e os deprimem. É com o apoio da família que conseguem superar o impacto de estarem impossibilitados de fazer algo. É interessante perceber que este é o grupo que demora para ir à procura médica, por considerar os sintomas como uma indisposição qualquer. Quando chegam ao CS, a doença já está em fase mais adiantada e, para a grande maioria, é necessário um período de repouso e licença do trabalho, para melhor recuperação. Quanto aos resultados finais do tratamento é um grupo que adere mais regularmente como um todo.

As mulheres casadas (do estudo) preocupam-se bastante pelo fato de estarem doentes. A sensação de culpa, por terem trazido a doença para dentro de casa, faz com que tenham cuidados maiores do que teriam em outra situação de doença não contagiosa. Procuram manter distantes seus pertences, em especial, para não contaminar outros familiares. Todas tinham uma preocupação maior com a saúde dos filhos e a proximidade direta deles com a tuberculose. Consultam mais freqüentemente os médicos, não do CS, mas dos locais onde costumam ir. A relação estabelecida com os médicos do CS é bastante vaga. Os médicos são considerados necessários, em princípio, para obter os medicamentos e não para esclarecêlas. Recorrem a outras fontes de informação, a fim de aprender mais sobre a doença com o 
objetivo de prevenção de reinfecção, sendo essas fontes: outros médicos, familiares próximos e livros.

Em geral, com exceção de duas entre as nove das mulheres casadas, dependem dos maridos para seu sustento; trabalham e auxiliam na manutenção do lar. Estas duas mulheres casadas são um exemplo de situações bastante específicas e não reducionistas. As restantes são sustentadas financeiramente pelos seus maridos e uma delas tem a aposentadoria como fonte de renda. Contudo, de modo geral, as mulheres casadas aderem à terapêutica, ingerem mais regularmente os medicamentos e fazem os exames mensalmente, mais do que as solteiras e os homens solteiros e separados; equivalem, em comportamento, ao dos homens casados. Estão mais atentas ao corpo, questionando constantemente o porquê de determinadas sensações corporais. Suas atitudes expressam a necessidade de manter a família distante de doenças, problemas e preocupações, cumprindo um papel de mulheres "provedoras" da tranqüilidade familiar.

Enfim, a intenção em fazer classificações analíticas entre solteiros, casados e separados, para gêneros opostos, expressam como o Ser (homem e mulher) está se manifestando nos diferentes momentos de vida - dentro dos quais os compromissos com sua rede social e os papéis sociais esperados e cobrados são diversos -, permitindo um campo de articulação e expressão de comportamentos, que se chocam com a hegemonia institucionalizada (não individualização) pelo PCT a todos os doentes. O processo de cura atual leva em consideração as questões ditas como "científicas", porém não individuais/sociais. Entretanto, resumir a discussão a uma reeducação necessária dos médicos e dos pacientes é deixar à margem um pro- blema mais amplo - os mecanismos e as políticas de saúde presentes no sistema de cura. São questões que envolvem, entre outras tantas, a estrutura de funcionamento dos locais, a qualidade de atendimento, a remuneração dos profissionais, a disponibilidade de recursos. Traz em seu âmago, também, realidades do convívio entre diferentes; a própria história da medicina social tem sido construída em cima dessas dificuldades. O tratamento atual, feito para a tuberculose, não foge a essa regra. Historicamente a educação popular feita com cartazes ou notas na imprensa não tem se mostrado eficiente para manter a população imune à tuberculose e nem mesmo próxima da cura quando em tratamento. Os dados epidemiológicos de incidência e não adesão confirmam isso. Assim sendo, um programa como o da tuberculose, idealizado e colocado em prática há mais de 20 anos, está baseado em uma discussão que se resume ao plano clínico/médico. Não abarca, na prática dos indivíduos doentes, o problema social da doença, exceto, por sua gratuidade e atendimento ambulatorial. Como tornar as $d i$ ferenças relevantes para a cura, no espaço da consulta médica, continua sendo uma tarefa importante, quiçá para o próprio ensino acadêmico da medicina.

No entanto, o que este estudo destaca é que as características sociais imputadas aos gêneros estão por trás de uma série de comportamentos que afetam diretamente a forma como os pacientes lidam com seu tratamento, seu corpo, com o fato de estarem doentes e conviverem socialmente. O momento de vida em que cada paciente se encontra (aliado ao que lhe é requerido como homens e mulheres) impõe relações e atitudes que, por vezes, favorecem a não adesão ao tratamento do que a cura (da forma estipulada).

\section{Agradecimentos}

Ao Conselho Nacional de Desenvolvimento Científico e Tecnológico - CNPq, ao Programa de Dotações para Pesquisa da Associação Nacional de Pós-graduação em Ciências Sociais - ANPOCS, com recursos da Fundação Ford e ao Departamento de Medicina Social/Centro de Pesquisas Epidemiológicas/Universidade Federal de Pelotas. 


\section{Referências}

BARNHOORN, F. \& ANDRIAANSE, H., 1992. Search of factors responsible for noncompliance among tuberculosis patients in Wardha District, India. Social Science and Medicine, 34:291-306.

BERTOLOZZI, M. R., 1998. Adesão ao Programa de Controle da Tuberculose no Distrito Sanitário do Butantã, São Paulo. Tese de Doutorado, São Paulo: Faculdade de Saúde Pública, Universidade de São Paulo.

BLOOM, B. R. \& MURRAY, C. J., 1992. Tuberculosis: Comentary on a reemergent killer. Science, 257: 1055-1064.

CHAULE, P., 1990. Compliance with chemotherapy for tuberculosis: Responsabilities of the health ministry and of physicians. Bulletin of the International Union Against Tuberculosis and Lung Disease, 66(Sup.):33-35.

CONRAD, P., 1985. The meaning of medications: Another look at compliance. Social Science and Medicine, 20:29-37.

DIAS-DA-COSTA, J.; GONÇALVES, H.; MENEZES, A. M.; DEVENS, E.; PIVA, M.; GOMES, M. \& VAZ, M., 1998. Controle epidemiológico da tuberculose na cidade de Pelotas, Rio Grande do Sul, Brasil: Adesão ao tratamento. Cadernos de Saúde Pública, 14:409-415.

DIMATTEO, R.; SHERBOURNE, C.; HAYS, R.; ORDWAY, L.; KRAVITZ, R. L.; McGLYNN, E.; KAPLAN, S. \& ROGERS, W., 1993. Physicians' characteristics influence patients' adherence to medical treatment: Results from the medical outcomes study. Health Psychology, 12:93-102.

DIXON, B., 1981. Além das Balas Mágicas: A Medicina Hoje, Acertos e Desarcertos. São Paulo: Edusp.

FARMER, P., 1997. Social scientists and the new tuberculosis. Social Science and Medicine, 44:347358.

FARMER, P.; ROBIN, S.; RAMILUS, L. \& KIM, J. K., 1991. Tuberculosis, poverty, and compliance: Lessons from rural Haiti. Seminars in Respiratory Infections, 6:254-260.

FOX, W.; PRABHAKAR, R.; GANAPATHY, S. \& SOMASUNDARAM, P., 1987. An inquiry into the attitudes of South Indian patients to the coloration of the urine by Rifampicin. Tubercle, 68:201-207.

GARRITY, T. F., 1981. Medical compliance and clinician-patient relationship: A review. Social Science and Medicine, 15:215-222.

GOFFMAN, E., 1988. Estigma: Notas Sobre a Manipulação da Identidade Deteriorada. Rio de Janeiro: Editora Guanabara.

GONÇALVES, H., 1998. Corpo doente: Um estudo sobre a percepção corporal da tuberculose. In: Doença, Sofrimento, Perturbação: Perspectivas Etnográficas (L. F. Duarte \& O. F. Leal, org.), pp. 105120, Rio de Janeiro: Editora Fiocruz.

HAYNES, B.; TAYLOR, W. \& SACKETT, D., 1979. Compliance in Health Care. Baltimore: Johns Hopkins University Press.

HAYES-BAUTISTA, D., 1976. Modifying the treatment: Patient compliance, patient control and medical care. Social Science and Medicine, 10:233-238.

HULKA, B. S.; KUPPER, L. L.; CASSEL, J. C. \& BABINEAU, R., 1975. Medication use and misuse:
Physician-patient discrepancies. Journal of Chronic Disease, 28:7-21.

LEFÈVRE, F., 1991. O Medicamento como Mercadoria Simbólica. São Paulo: Editora Cortez.

LIEFOOGHE, R.; MICHIELS, N.; HABIB, S.; MORAN, M. B. \& DE MUYNCK, A., 1995. Perception and social consequences of tuberculosis: A focus group study of tuberculosis patient in Sialkot, Pakistan. Social Science and Medicine, 41:16851692.

MANGTANI, P.; JOLLEY, D. J.; WATSON, J. M. \& RODRIGUES, L. C., 1995. Socioeconomic deprivation and notification rates for tuberculosis in London during 1982-91. British Medical Journal, 310:963-966.

MENEGONI, L., 1996. Conception of tuberculosis ant therapeutic choices in Highland Chiapas, Mexico. Medical Anthropology Quarterly, 10:181-401.

MENEZES, A. B.; DIAS-DA-COSTA, J. S.; GONÇALVES, H.; MORRIS, S.; MENEZES, M.; LEMOS, S.; OLIVEIRA, R. \& PALMA, E., 1998. Incidência de fatores de risco para tuberculose em Pelotas, uma cidade do sul do país. Revista Brasileira de Epidemiologia, 1:50-60.

MURRAY, C. L.; STYBLO, K. \& ROUILLON, A., 1990. Tuberculosis in developing countries: Burden, intervention and cost. Bulletin of the International Union Against Tuberculosis and Lung Disease, 65:6-24.

NAIR, D. M.; GEORGE, A. \& CHACKO, K. T., 1997. Tuberculosis in Bombay: New insights from poor urban patient. Health Policy and Planning, 12:7785.

PERINI, E., 1998. O Abandono do Tratamento da Tuberculose: Transgredindo Regras, Banalizando Conceitos. Tese de Doutorado, Belo Horizonte: Escola de Veterinária, Universidade Federal de Minas Gerais.

PICON, P.; RIZZON, C. F. \& OTT, W. P., 1993. Tuberculose: Epidemiologia, Diagnóstico e Tratamento em Clínica e Saúde Pública. Rio de Janeiro: Medsi.

ROZENFELD, S., 1989. Avaliação do uso dos medicamentos como estratégia para reorientação política dos insumos de saúde. Cadernos de Saúde Pública, 5:388-402.

SBARBARO, J. A., 1980. Public health aspects of tuberculosis: Supervision of therapy. Clinics in Chest Medicine, 1:253-263.

SUMARTOJO, E., 1993. When tuberculosis treatment fails: A social behavioral account of patient adherence. American Review of Respiratory Disease, 147:1311-1320.

TROSTLE, J. A., 1988. Medical compliance as an ideology. Social Science and Medicine, 27:1299-1308.

WHO (World Health Organization), 1997. Report on the Tuberculosis Epidemic 1997. <http://www. who.ch> 